\title{
DO CINEMA AO GIF: APROPRIAÇÕES E RESSIGNIFICAÇÕES DA IMAGEM NO SÉCULO XXI
}

\author{
Flóra Simon da Silva ${ }^{1}$
}

\section{Introdução}

As novas tecnologias de produção de imagens, como o celular e de reconhecimento como a internet, permitem que a sociedade produza e reconheça através da imagem fotográfica e vídeos amadores, os registros históricos do cotidiano de sociedades em condições diversas. Esses registros, que eram restritos a jornais, revistas e tv (estruturados em uma visão de mundo segundo esses veículos de comunicação para espectadores com acesso a esses meios), na era digital tornam-se acessíveis (produção e recepção) participando ativamente do imaginário social. Usuários desses meios digitais não só consomem estas imagens e as redistribuem em redes sociais, mas as transformam em situações cotidianas afirmando-as em seu contexto social. Rosa (2016: 6) explica que imagens que são veiculadas através de mídias, sejam impressas ou virtuais, acabam promovendo o imaginário coletivo principalmente por "sua inscrição na circulação intermidiática ou interdispositivo". Nesse caso, a circulação de imagens na internet, que podem ser originadas em outros dispositivos (como o cinema), gera um fluxo contínuo de temas variados. Essas sociedades promovem novas relações com as imagens frente à acontecimentos que as incluem como protagonistas (produtores e receptores). Em uma perspectiva relativa a isso e aos novos modos em que a sociedade cria aparatos tecnológicos para comunicar, ao passo que existam ralações interacionais entre indivíduos, propomos aqui, a partir do autor José Luiz Braga o conceito da midiatização. Braga (2012: 35) afirma que esse conceito visa entender os processos "cujas ações não se restringem ao objeto "meios" nem ao objeto "receptores e suas mediações", mas os incluem, a ambos, em formações muitíssimo diversificadas e ainda articulados a outras formações". O conceito da midiatização "articula velhas formas de interação com as formas virtuais de vida" (Fausto Neto, 2006: 9). Assim, nesse novo ambiente estruturado pelas formas tecnológicas que dinamizam interações sociais, as

\footnotetext{
${ }^{1}$ Universidade de Caxias do Sul, Brasil. Email: florassilva@yahoo.com.br ORCID id: http://orcid.org/0000-0003-2773-826X
} 
sociedades em processo de midiatização não possuem estrutura linear em sua comunicação. Nesse caso, o conceito da midiatização é utilizado para explicar o modo como essas sociedades desenvolvem por meios técnicos, novas formas de comunicação e como são permeadas por eles. Em consequência, as interações sociais que são envolvidas nesses processos fornecem produção de sentido,

\begin{abstract}
Um deles, processo tecnológico, corresponde à disponibilização de ações comunicativas midiatizadas para largas parcelas da população, dosando e redirecionando a comunicação massiva. O outro, processo social, diz respeito a uma entrada experimental de participantes sociais nas práticas e processos antes restritos à indústria cultural - por crítica social, por reivindicações de regulação pública da indústria, por ações sociais organizadas para ocupar espaços de produção e difusão; e certamente pela ativação crítica e intencionada das mediações culturais, por apropriações "em desvio" das interpretações preferenciais da produção. (Braga, 2012: 34)
\end{abstract}

A partir disso, no momento em que observamos as dinamizações no envolvimento entre esferas da sociedade, definimos o conceito de midiatização como uma mudança cultural na sociedade, através do desenvolvimento de dispositivos tecnointeracionais. Segundo o autor, as sociedades organizam sua realidade a partir destes processos, por meio de aparatos tecnológicos, sendo que esses processos interacionais estão em contínuo movimento, pois a necessidade de comunicação está sempre evoluindo e se modificando.

Com base no conceito da midiatização nesse caso, o cinema, por meio da evolução tecnológica, passa a constituir não somente uma forma de recepção para os espectadores, mas também ser usufruo e apropriação pela sociedade, constituindo desvios no seu conteúdo original. Partimos dessa perspectiva pelo fato de a sociedade apropriar-se de materiais cinematográficos e os transforma em outros materiais comunicativos como forma de transmitir experiências cotidianas, a partir do momento em que a tecnologia permite estas apropriações. Para Proulx (2013), a apropriação deve ser entendida como o uso de objetos técnicos para materializar um produto e provocar sua circulação,

Se tomarmos mais a vertente positivista, observamos a emergência de usos e práticas improváveis, todas as práticas de fãs, de remixagens, mas ao mesmo tempo nos deparamos com extrema dificuldade prática para descrever e absorver adequadamente as práticas dos internautas; são efêmeras, espontâneas, inesperadas, mas que deixam rastros. Deparamo-nos com problemáticas de hipertextualidade, multimodalidade, intertextualidade. (Proulx, 2013: 91) 
Segundo o autor, os usuários são indivíduos que "selecionam, orientam, recebem, interpretam, remixam, criam, transmitem mensagens" (Proulx, 2013: 91), portanto, conteúdos criados por eles nos meios são os elementos centrais do novo ambiente da informação. É através dos meios digitais que eles adquirem as atividades de criação em suas práticas que os tornam os construtores de sua própria cultura midiática. Assim, não se deve mais pensar somente em como esses usuários interagem com o conteúdo, mas o que eles estabelecem com o conteúdo na sua vida cotidiana e pública.

\begin{abstract}
Quando falamos em apropriação, não há simplesmente o domínio técnico do objeto; há também um gesto de integração com a vida cotidiana. Ou seja, se você apenas domina o objeto técnico sem integrá-lo à sua vida profissional, pessoal, doméstica, não há, na nossa opinião, uma verdadeira apropriação. Em última instância, esse gesto criativo do uso leva, possivelmente a uma reinvenção da prática. Diríamos que o consumo está ligado ao campo do marketing, dos estudos da difusão. A utilização está mais ligada à ergonomia das interfaces, e a apropriação está mais ligada à sociologia da apropriação. (Proulx, 2016: 46).
\end{abstract}

Logo, para que exista apropriação do objeto técnico, deverá existir nesse processo a sua função integrada à vida pública. Ao ser acessado, este deverá ter alguma utilidade na vida cotidiana e em consequência disso, o uso deverá abrir possibilidades para novas criações. Consequentemente, as práticas de usos da tecnologia na era digital estão voltadas ao crescente número de usuários online, pois estamos constantemente conectados. Os usuários são participantes que criam e inovam por meio dos usos que fazem de ferramentas disponíveis na internet. Constata-se nesse caso que as imagens de filmes, quando ofertadas na internet, sejam em sites de download, sejam em plataformas streaming, permitem que atores sociais as utilizem sejam como imagem estática ou em movimento. O filme proporciona apropriações de suas cenas e imagens, uma vez que esse material pode ser obtido por indivíduos nos meios digitais. Essas cenas são transformadas em gifs animados ${ }^{2}$ que expressam sentimentos ou opiniões de atores sociais. Por conseguinte, o cinema passa a ter seus conteúdos midiatizados e

\footnotetext{
${ }^{2}$ Um tipo de arquivo Gif que ficou popular em meios digitais foi o Gif animado, esse Gif é composto por várias imagens em formato Gif, que juntas, dão a sensação de movimento para a imagem, normalmente captam pequenos movimentos que se repetem. O formato Gif tem paleta de cores reduzido, o que na prática não é muito utilizado para fotografias, para tanto, é muito utilizado para pequenas animações. Nesse caso, utilizado para fazer pequenos recortes em cenas de filmes. Retirado de http://www.techtudo.com.br/artigos/noticia/2012/04/o-que-e-gif.html em janeiro de 2020.
} 
modificados pelas apropriações gerando novas formas de interações entre os espectadores - produtores de novos sentidos e memórias que são compartilhadas nesses meios.

\section{Cinema e tecnologia: a origem das ações}

No momento em que a virada das tecnologias ao digital influencia tanto a participação do sujeito quanto os objetos em si, encontram-se em diversas linhas de pensamento, diálogos entre autores e tentativas de solucionar os fenômenos comunicacionais que podem ser observados a partir dessas mudanças nos meios digitais.

Percebemos que nossas vidas são circundadas pelas novas tecnologias da comunicação e que assim somos levados a desenvolver novos métodos de comunicação. Aperfeiçoamos o original transformando materiais criados a partir deles, sempre em um processo contínuo de desenvolvimento: modificamos o objeto, porém o objeto também modifica nossa forma de viver. Segundo Latour (1992), nosso dia a dia é organizado por materiais não humanos, que comandam e ordenam nossa vida principalmente no momento em que caminhamos para uma hegemonia tecnológica, ao passo que constantemente precisamos desses objetos para viver.

O cinema, por exemplo, tem a sua história em um desenvolvimento tecnológico material: as diversas técnicas ajustadas em seu funcionamento que integram a invenção do cinetoscópio $^{3}$ de Thomas Edison, à projeção de filmes a um público maior, proporcionada pelos irmãos Lumiére, até a evolução das salas cinema. O avanço tecnológico do equipamento que passou por mudanças nos suportes fílmicos inicialmente, hoje engloba as câmeras digitais em dispositivos móveis como o celular, simplificando a utilização da câmera, possibilitando a amadores a documentação, reprodução e compartilhamento digital de suas memórias. Desse modo, não há como

\footnotetext{
${ }^{3}$ O Cinetoscópio é um instrumento de projecção interna de filmes inventado por William Kennedy Laurie Dickson, chefe engenheiro da Edison Laboratories de Thomas Edison, em 1889, e patenteado por Edson em 1891. É um sistema de engrenagem para uma tira de $15 \mathrm{~m}$ de película de celulóide e permitia a obeservação através de um furo (as imagens só podem ser vistas por um espectador de cada vez). Foi o precursor de todos os aparelhos de filmagem e a largura de seu filme, de $35 \mathrm{~mm}$, passou a ser considerada internacionalmente. Retirado de https://mariaeusebio12av1.wordpress.com/historia/brinquedosopticos/cinetoscopio/ em janeiro de 2020
} 
dissociar os estudos ser humano e do não humano, (Latour, 1992), pois modificamos e somos modificados, mas existem maneiras de observar o objeto como transformador do mundo, constituindo interações sociais.

O cinema é um dispositivo de reprodução que produz informação material em suporte fílmico ou digital, que pode ser repetido indeterminadas vezes, pública ou individualmente, transformado em um objeto social no momento em que possibilita a circulação da informação entre diferentes culturas, constituindo essa informação material ou imaterial, concreta e simbólica. O cinema é um modo de reprodução do real que se molda através da percepção do espectador em uma estrutura formada através da linguagem determinada pela vontade de seu realizador. Ele estabelece sentidos ao conteúdo fílmico transmitindo sensações ao espectador. Nesse caso, como dispositivo e meio de comunicação, permite à instituição cinematográfica fixar mensagens ao seu público através da projeção de conteúdos diversos. Nesse caso, ele sempre foi visto como uma indústria midiática, porém, é o conteúdo fílmico que, ao ser disponibilizado nos meios digitais, permite seu compartilhamento e modificação de sentidos originais. Assim, transforma interações ao formar novos materiais apropriados e exteriorizados por atores sociais, constituindo novos fenômenos midiáticos que "produzem a autonomia de emissores e receptores, e a persistência dos discursos pelo tempo" (Verón, 2014: 17).

Desenvolvido em suas tecnologias e linguagens, o cinema adaptou histórias da literatura utilizando linguagens já consolidadas adequando-as às novas estruturas visuais - imagens em movimento. Em seu seguimento, textos originais foram criados exclusivamente para o cinema considerando sua linguagem visual específica e sua capacidade de reprodução. Essa capacidade possibilita o espectador do século XXI assistir à um filme produzido no início do século XX, tornando presente acontecimentos cotidianos passados, e tal qual na imagem fotográfica "o passado seria apenas um presente antigo [...], poder-se-ia passar gradualmente de um para outro, e recompor o passado com o presente" (Rouillé, 2009: 218).

Para Almeida (1999), o cinema cria ficção e realidades históricas, produzindo memória. Considera que essa arte é também um artifício que produz conhecimento real além das práticas da vida cotidiana. Assim, o cinema não participa da história somente como técnica, mas como arte e ideologia. 
IMAGENS de catástrofes, IMAGENS fantásticas, IMAGENS violentas e ensanguentadas, IMAGENS de ambientes aristocráticos, nobres, burgueses, plenos de decoração, maravilhosa, IMAGENS de seres extraterrestre, grotesco, híbridos, IMAGENS angelicais, IMAGENS infernais, povoam os afrescos em movimento no cinema. Não somente essas, mas todas as imagens que vemos no cinema, devido ao tamanho enormecido e aos planos de aproximação e close, por exemplo, em que aparecem na tela são também forma fantásticas. Em todos os gêneros, mesmo em seu gênero 'cult, artístico, intelectual', o cinema e, também a televisão, revelam-se uma arte da memória e seus trajetos originários enlaçam, num certo momento da história, o Ad Herennium e participam da memória coletiva, histórica. (Almeida, 1999: 55-56)

O cinema, como instituição, expressa valores e mensagens e, para o autor, participa da construção mítica da sociedade contemporânea. "Participam tanto da narração quanto das figuras morais e modelares das virtudes e dos vícios” (Almeida, 1999: 58).

Da mesma forma, ao definir a instituição, Hjarvard (2014: 25) propõe que essas "estruturas dinâmicas que proporcionam às organizações e indivíduos recursos materiais e simbólicos" têm como objetivo proporcionar conteúdo de forma que possa "agir reflexiva e criativamente em circunstâncias variadas e, assim, possivelmente renovando as próprias instituições”. Dessa forma, é possível pensar que o cinema, na teoria clássica como meio, ou como mediador, antes proporcionava material simbólico ao espectador. Hoje, no entanto, além de proporcionar material simbólico, é possível o adaptar em outros suportes através do engajamento do ator social, que se apropria do material nos meios digitais, transformando novos sentidos através da lógica estrutural ou material fílmico, atualizando-o em outras dinâmicas. A partir disso, os materiais das instituições, antes simbólicos, hoje são acessados e apropriados nos meios digitais de forma que modificam sentidos. Envolvem interações da sociedade que, ao utilizar as mídias no seu cotidiano, desenvolvem novas práticas de comunicação.

$\mathrm{O}$ autor explica que esse movimento acontece a partir da mudança nas mídias contemporâneas nas quais a comunicação está sendo complementada por mídias interativas, possibilitando não só receber, "mas também se engajar ativamente em diversas formas de comunicação com alcance potencialmente global" (Hjarvard 2014: 25), integrando essas novas mídias nas práticas cotidianas. Dessa forma, essa mudança não é somente técnica na comunicação da vida familiar, mas também afeta as relações "entre mídia, cultura e sociedade". O autor define que a midiatização se preocupa com as transformações nas interações dos atores sociais e as instituições. Ela caracteriza-se 
por ser um processo recíproco entre as mídias e os outros campos sociais. O cinema, em meio à isso, origina imagens e dessas imagens, memórias e sentidos ao espectador, que escolha apropriar-se de cenas que são associadas à vivências e experiências de seu cotidiano, externando a ideia por meio de outro material visual similar ao cinema (imagem em movimento), o gif animação.

\section{Ressignificações da imagem: o gif como dispositivo tentativo e simbólico do século XXI}

Ao observar como um filme antes era produzido pela instituição cinematográfica, projetado nas salas de cinema e mais tarde disponibilizado ao espectador no formato de material físico, considerava-se que o espectador se apropriava de sua ideia, sua estética, cópia ou diversas outras formas de apropriação intelectual. No entanto, não tinha como alterá-lo manual ou digitalmente, pois necessitaria de aparatos tecnológicos avançados, dos quais o acesso seria restrito e um saber específico que muito provavelmente não lhe estava disponível. Entretanto, a disponibilidade dos materiais fílmicos em meios digitais aumentou e o acesso a filmes cresceu através de downloads e compartilhamentos dos atores sociais em plataformas como o Youtube e nas páginas de armazenamento de filmes e séries. Hoje, porém, seu conteúdo, o filme, passa pelo processo de midiatização quando lhe são vinculados novos sentidos a partir de seu original, quando lançados novos materiais nos meios digitais, iniciando circuitos complexos. O processo de midiatização, segundo Verón (2014), inicia-se a partir de algumas condições na sociedade, que permitiram o surgimento dos fenômenos midiáticos,

Começando no início do século XIX, novos dispositivos técnicos permitiram o surgimento, pela primeira vez, de fenômenos midiáticos consistindo na produção inicial de imagens e sons que enquadram e sequenciam o tempo, dispositivos que culminam, no século seguinte, com a invenção da televisão. (Verón, 2014: 15) 
Em consequência dessas relações dispositivo/técnico interacional em relação ao cinema, consideramos o modelo de gif animação de cinema ${ }^{4}$ compartilhados em sites de armazenamento ou mesmo em páginas pessoais do Facebook, por exemplo, como consequência dessas escolhas comunicacionais. Eles aparecem como pequenos recortes de cenas de filmes que repetem movimentos ou ações de personagens de filmes, as vezes representando situações textuais que o desconectam de seu sentido original aferido pelo cinema.

Segundo Lupinacci (2016: 35), o fato do gif ser produzido em formato pequeno podendo ser reproduzido em diferentes plataformas, é vital para a circulação e "para sua aplicação em diferentes usos, com diversas intenções". Nesse caso o gif transforma-se em objeto que atribui características fáceis de identificar e de se apropriar. Dessa forma, com o recorte e a repetição de cenas que não são tão memoráveis no seu contexto original, o gif ganha um novo valor e potencializa a circulação. O gif constituiu um formato de arquivo leve podendo ser utilizado em diferentes plataformas.

Para Nadal (2014), é dessa forma que o gif torna-se ideal para ser veículo de pequenas animações.

Em seu nível técnico, pode-se dizer que os gifs são imagens voltadas ao meio virtual, dessa forma, são concebidos em resoluções mais baixas (entre 72 e 90 DPI). Sua natureza favorece para que o tamanho final do arquivo seja reduzido, contribuindo para um maior nível de compartilhamento da informação. Contudo, a tendência de desenvolvimento das tecnologias das telas pode influenciar estas imagens para que passem a ser criadas em dimensões maiores no futuro. (Nadal, 2014: 51)

$\mathrm{Na}$ criação do gif, o ator social pode utilizar um recorte de cena ou imagem de um filme onde o personagem da cena selecionada utiliza alguma expressão corporal que remete à algum acontecimento do cotidiano ou alguma situação que ocorreu a esse ator, que junto à uma legenda, pode produzir novos sentidos. Um exemplo dessa apropriação e ressignificação de elementos cinematográficos é o gif Confused Travolta ${ }^{5}$ que apresenta o personagem Vincent Vega, originado no filme Pulp Fiction (1994), em diversos contextos de gifs compartilhados nos meios digitais. Essa ação foi possível a

4 Recorte de uma cena de filme e transposta para o suporte de gif. Disponível em http://www.techtudo.com.br/artigos/noticia/2012/04/o-que-e-gif.html. Acesso em janeiro de 2020

5 Confused Travolta é uma série animada de GIF com um recorte do ator John Travolta no filme de 1994, Pulp Fiction, editado em outras imagens de base de vários contextos. Disponível em http://knowyourmeme.com/memes/confused-travolta. Acesso em janeiro de 2020 
partir de um tutorial ${ }^{6}$ criado em 2015 e compartilhado inicialmente no site Imgur $^{7}$, acolhido e utilizados por diversos atores sociais.

Os gifs são utilizados para representar situações e expressões e é com base no desenvolvimento dessa nova forma de comunicação que percebemos a proliferação desses materiais nos meios digitais. Isso ocorre pois, por meio de sites de armazenamento e downloads de filmes e sites que promovem ações que auxiliam a criação de gifs e como o site é possível que atores sociais criem expressões de vida apropriando-se de cenas ou imagens de filmes. Nesse caso a função da memória é ativada, ao passo que as imagens ou filmes são armazenados e acessados novamente na web, mesmo que exista um espaço de tempo entre a produção do filme e a sua apropriação nos espaços digitais.

\begin{abstract}
Partindo da ideia de que a web, assim como a mídia, é um espaço infinito de armazenamento de dados, observa-se que a função memória é ampliada neste meio uma vez que é possível acessar materiais já há algum tempo desaparecidos ou mesmo criar novos produtos a partir de outros já disponíveis. Neste sentido, no que tange às imagens percebe-se que as inscritas em dispositivos midiáticos jornalísticos como revistas, jornais e na própria televisão, por exemplo, voltam a ser inscritas em dispositivos de atores individuais potencializando a circulação intermidiática. (Rosa, 2014: 244)
\end{abstract}

Dessa forma, a imagem pode circular diversas vezes em diferentes lugares, sendo apropriadas e reinseridas por atores sociais, sem que haja restrição da instituição originária da imagem. Para a autora as imagens "são elaboradas, reelaboradas, replicadas, acrescidas de novos significados" (Rosa, 2016: 5) e isso faz com que os sentidos possam ser modificados divergindo com os sentidos primeiros, mas que, da mesma forma, os elementos visuais de composição da imagem continuem ligados à sua origem ou à instituição que os produziu, no caso o cinema. Nesse sentido, a apropriação do elemento fílmico permite levar adiante novos sentidos e transforma o gif em um suporte narrativo criado pelo ator social e não mais pela instituição cinematográfica, mas com lógicas da estrutura cinematográfica (movimento do gif), conjunto contexto e personagem, além da legenda, contando uma história curta, que, em circulação,

\footnotetext{
${ }^{6}$ Tutorial para montagem do gif Confused Travolta. Disponível em https://imgur.com/mkhFnmC Acesso em janeiro de 2020

${ }^{7}$ Site que disponibiliza imagens, memes e gifs. Disponível em http://imgur.com/. Acesso em janeiro de 2020
} 
transforma o sentido a partir das interpretações observadas nos comentários e discussões nos meios digitais.

Rosa (2017) afirma que imagens em circulação constituem dois lados: de um lado, as imagens que integram nosso imaginário; de outro, as que exibem concretude material. As imagens podem ser documentais, constituindo fatos e acontecimentos, ou ficcionais, constituindo imagens do cinema por exemplo. Em diálogo com Belting, a autora dispõe que estes dois tipos de imagens são denominados respectivamente endógenas e exógenas. Ambas, porém, sofrem afetações mútuas, pois uma imagem exógena pode vir a integrar "o repertório iconográfico do indivíduo, transformando-se em endógenas". (Rosa, 2017: 330). Da mesma forma, as endógenas podem vir a se transformar em exógenas por meio de produções do ator social ou da instituição. As imagens classificadas como endógenas podem ser postas em circulação no momento em que o ator social ou a instituição materializa imagens em exteriorizações, como a fotografia, por exemplo. Estes materiais podem ser absorvidos transformando-se em endógenas, ficando suscetíveis à fixação no inconsciente de atores sociais para serem novamente transformadas em outro formato mais adiante.

Dessa forma, essa ideia ou conceito que o personagem adquire através de suas ações no filme, permite que o espectador faça conexões com algum formato arquetípico pré-concebido em seu inconsciente. Jung (2000) explica que os arquétipos formam-se por meio de uma psique pré-formada de acordo com a espécie. Ele denomina essas formas como imagens e afirma que elas são primordiais, sendo originadas no início da espécie humana, herdadas de geração em geração. Para o autor, os arquétipos "ressurgem espontaneamente em qualquer tempo e lugar, sem a influência de uma transmissão externa" (Jung, 2000: 90) e tornam-se conteúdos somente quando preenchida com material do consciente,

\footnotetext{
No tocante ao caráter determinado da forma, é elucidativa a comparação com a formação do cristal, na medida em que o sistema axial determina apenas a estrutura estereométrica, não, porém a forma concreta do cristal particular. Este pode ser grande ou pequeno ou variar de acordo com o desenvolvimento diversificado de seus planos ou da interpenetração recíproca de dois cristais. O que permanece é apenas o sistema axial em suas proporções geométricas, a princípio invariáveis. $\mathrm{O}$ mesmo se dá com o arquétipo: a princípio ele pode receber um nome e possuir um núcleo de significado invariável, o qual determina sua aparência, apenas a princípio, mas nunca concretamente. (Jung, 2000: 91)
} 
Sendo o arquétipo a estrutura primordial, relaciona-se ao cinema quando um personagem de um filme gesticula ou age de determinada forma associando-se à outras imagens primordiais inconscientes do espectador que podem ser coletivas, ou seja, complementar as mesmas ideias de outros espectadores que percebem ou convocam as mesmas imagens primordiais nesse personagem. Para Flusser (1994:11), o gesto define uma intenção, "o gesto o é porque representa algo, porque é somente com ele que se trata de dar sentido a algo" 8 , e somente o interpretamos pois relacionamos com situações que o podem ter provocado. Entretanto, de forma a deixar clara a sua reação a essa situação, o produtor pode ancorar sentido à imagem através de um texto explicativo, pois, mesmo que outros espectadores identifiquem o gesto, "a mensagem linguística orienta não mais a identificação, mas a interpretação, constitui uma espécie de barreira que impede a proliferação dos sentidos conotados" (Barthes,1990: 33). A ação de apropriar-se da imagem desse personagem ou de sua ação na cena é escolha de cada espectador, que nesse caso passa a ser produtor de sentido quando escolhe concretizar esse arquétipo em uma imagem e texto, compartilhando uma emoção ou expressão através daquele personagem. Assim fará com que outros indivíduos reconheçam imagem e texto como suas, compartilhando a mesma expressão em diversos meios digitais. A imagem é um símbolo que faz a mediação entre o espectador e a realidade, (Aumont, 1995), e essa relação entre o espectador e a imagem é uma atividade recíproca, pois, ao mesmo tempo em que o espectador a constrói, ela também o constrói porque fará parte de suas memórias, isto é, integralizará sua experiência e a possibilidade de rememoração.

As imagens antes originadas pela instituição cinematográfica, agora passam a ser apropriadas por atores sociais que as adaptam em expressões cotidianas, ressignificando as nos meios digitais para outros atores sociais, comunicando novas situações através de gestos e composições visuais. Da mesma forma, o cinema faz quando adapta uma cena de filme em outro filme utilizando elementos visuais referências do filme original, ou quando cria memórias artificiais, (Almeida, 1999), em um mundo imaginado, mas que traz características de situações reais que fazem conexões com o que o espectador conhece em sua vida cotidiana.

\footnotetext{
${ }^{8}$ Tradução própria.
} 
Para além da reformulação da estrutura comunicacional pela midiatização, novas memórias a partir de imagens originadas no cinema são construídas para significar sentimentos de atores sociais e mais do que isso, expressam valores e ideias consumidas e compartilhadas pela sociedade contemporânea. Os gifs promovem trocas significativas entre atores sociais nos meios digitais, possibilidades de interação com outros indivíduos da sociedade e descobertas de novos meios de comunicação, atribuídos não somente às instituições, mas a partir das práticas culturais de consumo e produção, que levam também à proliferação de imagens nos meios. Novas memórias e histórias estão sendo desenvolvidas doravante as práticas de apropriação. Linguagem em que a imagem comunica, dá sentido, é ressignificada pelo texto.

$\mathrm{Na}$ sociedade em vias de midiatização, portanto, o cenário tecno-discursivo e as disputas de sentido entre produção e recepção, segundo Fausto Neto (2010), evidenciam uma nova forma de circulação de produtos materializados, complexificando os efeitos de sentido. Nessa sociedade, o receptor é reestabelecido na estrutura comunicacional. Ele se apropria de elementos presentes nos dispositivos digitais e os modificam produzindo outros sentidos, que convergem ou divergem dos sentidos primeiros. Essa problemática, da qual fala o autor, "deriva de um trabalho cuja realização e resultados não são produtos de uma atividade intencional, instaurando pactos simetrizantes entre os sujeitos", pois os trajetos e efeitos que relacionam a produção e recepção, resultam do circuito, "do qual é ele que define e impulsiona sobre quais condições se fundem as operações de sentido". (Fausto Neto, 2010: 9).

A midiatização permite a transformação do gif em um novo dispositivo tentativo, visto que o gif permite a materialização visual de novos sentidos que comunicam, mas que é produzida de atores sociais para outros atores sociais. Este novo dispositivo é agenciador de fluxos e conversações e permite, por meio de um objeto técnico, a transformação de significações anteriores em novas (cinema para o gif instituição para ator social).

\section{Considerações finais}

A origem do cinema permitiu a captação e reprodução de imagens em movimento, inicialmente possibilitou o arquivamento histórico do cotidiano de trabalhadores e sua saída da fábrica, de uma mãe alimentando o seu bebê e mesmo da 
documentação de espaços públicos e outras culturas, que antes somente eram conhecidas por meio de relatos, pinturas e fotografias. A possibilidade da cópia e reprodução da película fílmica permitiu que realizadores produzissem e exibissem situações cotidianas. O cinema evoluiu. Narrativas foram adaptadas da literatura, a linguagem cinematográfica renovada a partir do avanço tecnológico e das grandes produtoras, mas não deixou de ter como base a representação da história de sociedade, fosse ela verídica ou ficcional, através da imagem em movimento.

As práticas técnicas observadas nos meios, comuns na sociedade em midiatização, fazem com que os meios tradicionais como o cinema e seu conteúdo fílmico adaptem-se às lógicas criadas por atores sociais, servindo aos seus propósitos de comunicação. São referência, em um primeiro momento, como fornecedores de material simbólico e ao passo que são disponibilizadas ferramentas técnicas acessíveis nos meios digitais e a instauração de uma cultura que replica, valoriza, produz e cocria materiais, ocorrem novas formas de apropriações por atores que transformam o cinema e o filme. Os atores sociais, ao dedicarem atenção aos elementos cinematográficos, ao mesmo tempo, materializam produtos como os gifs fornecendo novos símbolos nos meios digitais. Esses símbolos, hoje, representam narrativas de situações cotidianas que inicialmente eram registradas pelo cinema e que agora, a partir das apropriações, criam novas memórias e histórias compartilhadas nos meios digitais, ressignificando imagens e memórias criadas pela instituição cinematográfica.

\section{REFERÊNCIAS}

ALMEIDA, Milton José de. Cinema: arte da memória. Campinas, SP: Autores Associados, 1999.

AUMONT, Jacques. A Imagem. 2.ed. São Paulo: Papirus, 1995.

BARTHES, Roland. O óbvio e o obtuso: ensaios críticos III. Rio de Janeiro: Nova Fronteira, 1990.

BRAGA, José Luiz. Circuitos versus campos sociais. In: MATOS, Maria Ângela; JANOTTI JUNIOR, Jeder; JACKS, Nilda Aparecida. Mediação e Midiatização: Livro Compós 2012. Salvador/Brasilia: UFBA/COMPÓS, 2012, p 28-52. 
FAUSTO NETO, Antônio. Midiatização, prática social - prática de sentido. $X V$ Encontro da Associação Nacional dos Programas de Pós-Graduação em Comunicação (Compós). UNESP - Bauru, SP, junho de 2006.

A circulação além das bordas. Mediatización, Sociedad y Sentido: Diálogos Brasil y Argentina. Rosário: UNR, 2010. p. 2-17.

FLUSSER, Vilém. Los gestos. Fenomenologia y comunicacion. 1994. Disponível em https://monoskop.org/images/c/cd/Flusser_Vilem_Los_gestos_Fenomenologia_y_comu nicacion.pdf. Acesso em janeiro de 2020.

GONZÁLES DE GOMES, Maria Nélida. A reinvenção contemporânea da Informação: entre o material e o imaterial. Tendências da Pesquisa Brasileira em Ciência da Informação, v. 2, 2009.

HJARVARD, Stig. Midiatização: conceituando a mudança social e cultural. In: Revista Matrizes. $\mathrm{N}^{\circ} 1,2014$, p. 21-44.

JUNG, G. Carl. Os arquétipos e o inconsciente coletivo. Editora Vozes. 2 ed. Petrópolis, 2002.

LATOUR, Bruno. Where are the missing masses, sociology of a few mundane artefacts. In Shaping Technology-Building Society. Studies in Sociotechnical Change, Wiebe Bijker and John Law (editors), MIT Press, Cambridge Mass. pp. 225-259, 1992

LUPINACCI, A. Ludmila. As apropriações do GIF animado: aspectos culturais, expressivos e afetivos dos usos de uma tecnologia defasada. Dissertação de Mestrado em Comunicação e Informação. UFRGS. 2016

NADAL, João, H.D. A cultura do gif: Reconfigurações de imagens técnicas a partir dos usos e apropriações de narrativas cíclicas. Dissertação de mestrado em Comunicação e Linguagens da Universidade Tuiutí do Paraná. 2014

PROULX, Serge. Paradigmas para pensar os usos dos objetos comunicacionais. In: PROULX, Serge; FERREIRA, Jairo; ROSA, Ana Paula (orgs). Midiatização e redes digitais: os usos e as apropriações entre a dádiva e os mercados. Santa Maria: FACOSUFSM, 2016, p. 41-78. 
ROSA, Ana Paula. Imagens-Totem em Permanência X Tentativas Midiáticas de Rupturas. In: ARAUJO, Denize Correa e CONTRERA, Malena Segura (orgs) Compós 2014. 368 p.

- Paradigmas para pensar os usos dos objetos comunicacionais. In:

PROULX, Serge; FERREIRA, Jairo; ROSA, Ana Paula (orgs). Midiatização e redes digitais: os usos e as apropriações entre a dádiva e os mercados. Santa Maria: FACOSUFSM, 2016, p. 71-97.

. Tensões entre o registro e a encenação: a imagem de Aylan Kurdi e sua constituição em totem. Revista Observatório, Palmas, v. 3, n. 1, p. 327-351, 2017. ROUILLÉ, André. A fotografia: entre documento e arte contemporânea. São Paulo: SENAC São Paulo, 2009

VERÓN, Eliseo. Teoria da midiatização: uma perspectiva semioantropológica e algumas de suas consequências. Revista Matrizes. São Paulo. Vol. 8, nº 1, 2014.

Recebido: $31 / 01 / 2020$

Aprovado: $15 / 07 / 2020$ 